\title{
Editorial
}

\section{At the end of the division of labor}

The most significant phenomenon is taking place, and for the first time in human history at that: the ancient process of the division of labor is slowing down, reversing itself, and starting to move in the direction of the re-integration and re-aggregation of labor and knowledge. Adam Smith's 'division of labor' has come to its end.

This amazing transformation, 'The Grand Reversal', has mostly escaped the attention of common economists.

Man has created an incredible number of progressively differentiated and different jobs, specialties, functions, markets and activities. At the same time, Man erected, mostly spontaneously and without conscious intention, a staggering complexity of requisite coordinative systems. The sheer number of levels and subdivisions of tasks, management specialties and necessary scheduling and coordinating interfaces has grown out of bounds.

Homo economicus has made the 'knowing more and more about less and less' the key to economic efficiency and productivity. That 'key' does not seem to be working any longer.

Today we install multi-purpose or general-purpose robots and computer-integrated systems, replacing the single-purpose and dedicated massproduction machinery; we reward multifunctional worker more and a single-task-efficient 'operator' less; instead of fixed ('bolted to the floor') systems we now crave Flexibility; instead of narrow experts and specialists we search for competent and creative generalists. The fast-track specialization is rapidly being replaced by job rotation, and the quick-fix training by a life-long education. We reward well-rounded, renaissance-type managers,

North-Holland

Human Systems Management 6 (1986) 97-99 while trying to lay-off the narrow specialists and number-crunchers of the times past (they do not even speak foreign languages); we search for men who are fluent with computers and leave the 'computer literacy' to the illiterate.

In short, we reward those who know more and more about more and more, and punish those who know more and more about less and less.

There are three basic manifestations of the 'Grand Reversal'.

(1) Specialization and division of labor is not only the oldest economic concept, but in fact the very cornerstone of all economics extant since Adam Smith's Wealth of Nations. Yet, it is increasingly self-evident that the greater the degree of specialization, the more steps have to intervene in the overall production process. Consequently, there are progressively increasing costs of coordination and management. At a certain point the costs of coordination and management exceed the achieved productivity benefits which are due to the finer atomization of tasks. The process of division of labor slows down and then reverses its course: towards re-integration and re-synthesis of work.

Ever expanding markets, which originally caused and allowed for the continuation of the divisional process of specialization, after crossing the 'breakeven point' of costs and benefits, play a major role in arresting this process and stimulating its reversal.

So we have 'single stimulus and multiple responses': a concept taken right from the pre-history of general theory of systems: an unstudied body of knowledge, especially by economists.

It is safe to state (and very difficult to explain) that western economists have so far ignored the coordination costs associated with the specialization and division of labor.

(2) As society's economic tasks and activities become dispersed into bits and pieces, the re- 
quisite integrative knowledge becomes similarly dispersed, incomplete, often contradictory, and possessed by an increasingly larger number of separate individuals. With the process of specialization and division of labor, the process of division of knowledge proceeds in step.

With the advancing specialization, the integration of the dispersed knowledge becomes more and more difficult to achieve and more and more costly to maintain: knowledge becomes a scarce, expensive, and most powerful economic resource.

It is safe to say (but hard to explain) that the concept of knowledge has been mostly ignored by economists. Yet the transformation to 'knowledge industries' has been under way for some time and knowledge has become the most important factor of production.

(3) The relatively high costs of more labor-intensive services are mandating an increasingly intensive search for technologies, knowledge and time that would jointly allow the consumer to acquire given service with the minimum number of intervening links, ultimately through a selfservice (i.e., zero number of intervening links).

The gradual transformation of self-service into the most efficient and most productive mode of human economic activity still goes largely unnoticed or ignored by traditional economists.

This process of re-capture of economic activities by the individual and family is not, of course, limited to self-service. The self-production (consumer becomes a producer at the same time) becomes also allowed by a new technology. The embedding of requisite knowledge in the technology allows the increasingly self-oriented service and production. Thus even the primary economic specialization, that into producers, service-providers and consumers, is gradually disappearing.

Artificial intelligence, expert systems, decision support systems, and similar high technologies are therefore important because of their ability to integrate knowledge, not because of their capacity to mimic overspecialized human experts: that goal belongs to their 'pre-history'. With the use of such integrative technologies, a human can perform larger variety of tasks, not a smaller number of narrower tasks.

To summarize the proposition:

Expanding economic markets allow for continually increasing specialization and division of labor and knowledge. Corresponding gains in productivity allow further shifts of labor into relatively less productive activities: from agriculture to industry, from industry to services. The 'distance' (number of intervening links) between the initial producer and final consumer is steadily increasing.

At the same time, the management costs of specialization are increasing: the needs for coordination, scheduling, management, control, planning, transportation, storage, and so on, are increasing. The rise of management as a function, the emergence of a service sector, and the growth of nation-state: all such phenomena are direct consequences of the need to cope with the management costs of specialization.

At a certain stage, the benefits of the additional specialization (division of labor) are exceeded by the management costs necessary to bring it about.

If we divide the task into thousands of subtasks, how difficult and how costly is it to assure that their proper sequencing, scheduling and interaction is maintained? If we divide the labor among thousands of 'partial' workers, how difficult and how costly is it to maintain their coordination, motivation and performance? If we divide the knowledge into thousands of tiny bits, how difficult and how expensive is it to achieve its necessary integration, record and update as a whole?

The answer to all three question is: progressively more difficult and progressively more expensive.

This process, characterized by two fundamentally different responses (division and integration) to the same stimulus (growth of markets) cannot be characterized as a 'cycle' or 'wave', nor as a 'revolution' or 'transformation', not even as a 'metamorphosis' or 'growth'. The closest description seems to be Giambattista Vico's conception of corsi e ricorsi in the history of social systems.

Any real origin in human affairs - and the process of division of labor is of a real origin meets with a real end. After each corso there follows a different and yet organically related recorso. There is a course and recourse, outswing and rebound, disaggregation and reaggregation. The process of corso and recorso cannot be divided or taken apart; it cannot be synthesized into higher order: it is a whole, a self-organizing and self-renewing whole. The success spawns failure 
and growth is also a decline. Every corso in human affairs is self-binding and self-limiting, transforming itself into its inevitable recorso.

The corso of the division of labor is an ancien régime, initiated concurrently with the emergence of human history. It has been expanding, exploding and diffusing itself incessantly. Only now, at the end of the twentieth century, the first manifestations of recorso of the division of labor (i.e., reintegration) can be observed. A long swing of recorso is ahead of us. It does not have to be as long and protracted as its corso: the rebound can be swift and vigorous.

Why is it at all possible that labor can be aggregated and knowledge re-integrated? Why is it possible now, at the end of the twentieth century?

As the division of labor progressed, the specialized efficiency of 'partial' workers was continually enhanced by dedicated, single-purpose machinery. Worker became an operator and necessary attachment to the machine. Worker supported and enhanced the machine, not the other way around.

From now on, for the first time in human history, it's going to be 'the other way around'.

Milan ZELENY

Graduate School of Business Administration Fordham University at Lincoln Center New York, NY 10023, USA 